\title{
Trends, drivers and barriers influencing Cloud Computing Services for mobile interactions in teaching and learning
}

\author{
Ronell van der Merwe \\ School of Computing, \\ University of South Africa, Pretoria \\ vdmerwer@unisa.ac.za
}

\author{
Judy van Biljon \\ School of Computing, \\ University of South Africa, Pretoria \\ vbiljja@unisa.ac.za
}

\begin{abstract}
The potential of cloud computing services (CCS) for supporting teaching and learning has been widely recognized, especially for mobile interactions. However, the multifaceted nature and rapid development of computing technology has complicated adoption and optimal application. This study investigated the trends, drivers and barriers influencing CCS for teaching and learning with mobile interactions both from a literature perspective and an educator's perspective. We structured the research in terms of three goals: The first goal was that of providing an overview of current literature on the topic of CCS for mobile interactions. To that end, a systematic literature review was conducted (literature from 2010 to 2016) to present an overview of the topics researched, as well as the determinants (including drivers and barriers) and opportunity areas in the field. The second goal was to get the perspective of educators on the determinants and enablers of CCS for teaching and learning with mobile interactions in the South African school context. Facilitators and teachers at South African schools in the Gauteng Province were interviewed towards obtaining that perspective. The third goal was to draw on the findings from literature and the insights gained from educators in South African schools towards identifying the barriers and enablers relevant to informing future research and practice.
\end{abstract}

Keywords - cloud-based storage; mobile cloud computing; cloud computing services; teaching and learning

\section{INTRODUCTION}

Cloud Computing (CC) is a paradigm for organizing and managing ICT resources. There are various definitions of cloud computing, one of which defines cloud computing as "a model for enabling convenient, on-demand network access to a shared pool of configurable computing resources (e.g., networks, servers, storage, applications, and services) that can be rapidly provisioned and released with minimal management effort or service provider interaction" [1].

Mobile cloud computing (MCC), a combination of mobile computing, cloud computing (CC) and wireless networks, provides a collaborative, rich environment for mobile interaction. MCC moves the processing and data storage away from the device into the cloud and offers the user an environment where the boundaries disappear between the various mobile platforms, storage space and functionalities. Figure 1 depicts the MCC environment, showing the main cloud computing components as being the servers, applications, storage facilities and software platforms and some of the devices used to access MCC. This diversity introduces complexity.

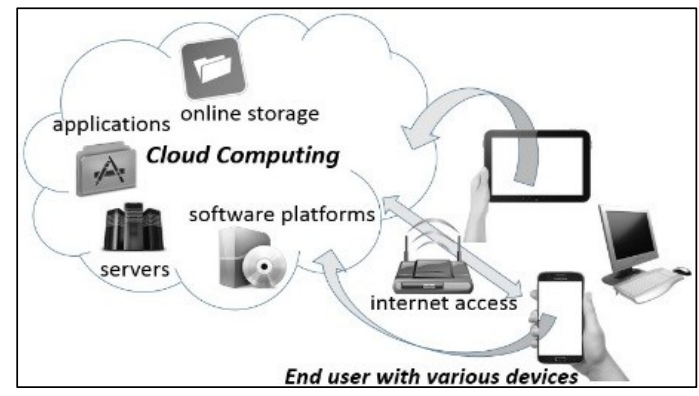

Fig. 1: Mobile cloud computing environment

The MCC phenomenon has been investigated from various angles including the ubiquity of technologies that support MCC in teaching and learning, the commercial value for developers of course materials for MCC, specific concerns that include the diverse selection of devices accessing the MCC, frequent disconnections, and mobility [2]-[5]. The multifaceted nature of cloud computing, including the different operational levels namely software as a service (SaaS), platform as a service (PaaS) and infrastructure as a service (IaaS), complicate the understanding and application [4] thereof in teaching and learning. The past two decades has seen the rapid progression from content-centric delivering and acquiring of online teaching and learning materials through learning management systems (LMS) to continuous and experience-centric learning portals that include Blogs, Wiki's and other similar social networks [6], [7]. During this period of adaption, MCC as a platform in teaching and learning evolved and continued to play an important role [5]. Despite the belief that MCC is a distraction [8] rather than a platform to a solution in teaching and learning, MCC holds promise for future development in education [5], [7]. Notwithstanding the growing interest in the use of cloud computing technologies in teaching and learning, the landscape has not been systematically described and delineated in terms of existing research. Furthermore, the views of educators on the use and usefulness of cloud computing is underrepresented. The

ISBN 978-1-5386-1000-8/18/\$31.00 (C2018 IEEE 
purpose of this study is to provide an overview of existing cloud computing research relating to teaching and learning and then to gain some insight into the view of educators, including facilitators and teachers. Facilitators' views are important due to their role not only in assisting educators in the development and implementation of curriculum but also through their role in policy formulation and implementation.

The paper is organized as follows: Section 2 firstly describes the systematic literature review as methodology and explains how it was applied in this study. Secondly, the data collection through interviews is described. Section 3 presents the results of the literature review, followed by the results from the interviews. Section 4 concludes with the findings.

\section{METHODOLOGY}

The systematic literature review process followed is described in section 2.1. Based on the findings from the systematic literature review, we identified research trends and opportunity areas. To investigate if the findings are relevant to the South African context, we conducted a series of interviews with educators (facilitators and teachers) in order to gain their perspective on the drivers, enablers and opportunity areas. The interview protocol is described in section 2.2 .

\subsection{Systematic literature reviews}

The purpose of a systematic literature review is to gather published research in a rigorous and systematic way, remove the irrelevant and redundant and then summarizing the most applicable to capture the essence of the science of systematic review [9]. The expansion of evidence-based practice in literature review has led to an increasing variety of review types; this can lead to a mismatch between the purpose and the methodology - if not understood well. Grant and Booth [9] published a typology based on the analysis of 14 review types; and based on their topology the systematic review type was selected. The characteristics of this review type are to systematically search for, appraise and synthesize research evidence of comprehensive scope with clear inclusion and exclusion criteria. The synthesis is narrative with tabular accompaniment. The systematic quantitative literature review method generally have three functions: (i) identifying, summarizing and critiquing current theory and methods; (ii) identifying ontological, epistemological and methodological problems and gaps; and (iii) providing much-needed evidence for decision makers when identifying and supporting priority issues [10].

The databases used in this study were Google Scholar, ACM, IEEE, Springer, and ERIC. The search was done for the publications from 2010 to 2017. The document types included were journal papers and conference papers (excluding keynote papers). The following search string was used: mobile AND technology AND "cloud computing" AND (teaching OR learning). Table 1 depicts the number of items found per database.

TABLE 1: DATABASES SEARCHED

\begin{tabular}{|l|l|l|}
\hline Database & Link & Total \\
\hline Google & https://scholar.google.co.za & 29,100 \\
\hline IEEE & Explore http://0-eeexplore.ieee.org & 42 \\
\hline ACM & http://dl.acm.org/ & 49 \\
\hline Springer & www.springer.com & 8,372 \\
\hline ERIC & http://eric.ed.gov/ & 10 \\
\hline
\end{tabular}

To make the selection comparable, we considered all the abstracts from IEEE Explore, ACM and ERIC and only the first 50 from Google Scholar and Springer. The 201 abstracts were read by the two authors independently. Duplicates were removed and the papers focused on the use of cloud computing for teaching or learning were selected. The individual sections were discussed to find consensus and 35 papers were selected for thematic analysis.

Those papers were added to a Mendeley group and read by two research assistants who independently abstracted the following detail for each paper in a separate table: title, purpose, research methodology and suggestions for future research. A thematic analysis was done on the table by highlighting the knowledge elements in each column and grouping those. The dimensions (categories) were identified and named on the basis of the frequency of the underlying knowledge elements or the potential for adding new insight. Some articles did not contribute any insights to a specific issue (topic, methodology or opportunity) and therefore only the relevant articles were cited. The analysis was done independently by the two authors and the results were discussed towards identifying the topics, methodologies and opportunities as presented in the next section. The process of searching the databases, and selecting and combining the results, is depicted in Figure 2.

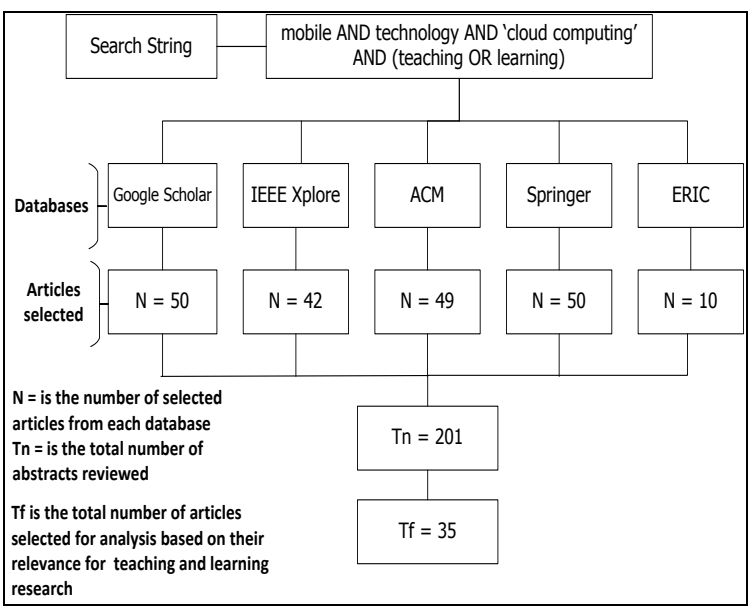

Fig. 2: Literature selection process

\subsection{Interviews}

Facilitators were included in the target group since they are an important part of the decision chain. One of the findings of our systematic literature review was that more guidance is required in terms of policies for implementing CCS and that is where the facilitators' community plays a pivotal role.

Telephonic interviews were conducted with 20 educators, including twelve facilitators and eight teachers. A semistructured, questionnaire-driven interview protocol was followed. The questionnaire was based on the insights gathered from the literature review then prioritizing those for the context of South African education. Ethical clearance for this study was obtained from the School of Computing's at UNISA ethical committee. The questionnaire is available from https://goo.gl/qB6yLE. The participants were selected from the Gauteng region. The 
researchers felt that data saturation was reached after interviewing 20 educators.

\section{RESULTS}

\subsection{Literature review results}

The results are presented by considering the research trends and the issues for future research.

\subsubsection{Research topics}

Considering research topics, the following main dimensions emerged from the thematic analysis: instructional, architectural and theoretical. The categories are depicted in Table 2 followed by references to articles in the category.

TABLE 2: RESEARCH TOPICS

\begin{tabular}{|c|c|}
\hline Categories & References \\
\hline $\begin{array}{l}\text { Instructional (new teaching approaches), } \\
\text { i.e. how to use the cloud to support } \\
\text { teaching and learning in practice }\end{array}$ & 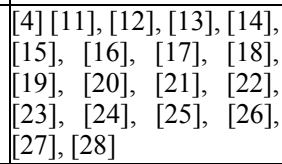 \\
\hline $\begin{array}{l}\text { Architecture (portability, interoperability } \\
\text { and } \\
\text { integration of teaching resources towards } \\
\text { building the platform) }\end{array}$ & 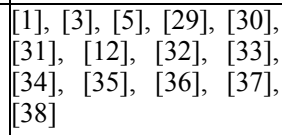 \\
\hline $\begin{array}{l}\text { Theoretical (models, frameworks and } \\
\text { taxonomies for understanding MCC and } \\
\text { theorizing the opportunities, challenges, } \\
\text { and benefits of using the technology) }\end{array}$ & $\begin{array}{l}{[6],[39],[8],[40],[41],} \\
{[42]}\end{array}$ \\
\hline
\end{tabular}

Within these broad categories the papers were read to identify concepts that could be considered drivers or challenges in using MCC technologies for teaching and learning. The following main categories emerged: (A) ubiquity of technology that support MCC as a teaching and learning environment; (B) data management in terms of context awareness and the identification of potential resources; (C) privacy, security and trust; and (D) risk management and assessment.

\section{Ubiquity of MCC technology}

Users of mobile technology are increasingly moving away from the use of personal computers to hand-held devices such as mobile phones and tablets [41]. The Mobile Africa 2015 survey of mobile phone usage in five African countries, namely South Africa, Nigeria, Kenya, Ghana and Uganda, delivered unexpected findings, for example that more than $40 \%$ of the users of mobile devices use it to browse the internet. Of the nearly 52 million people living in South Africa, more than 40 million have access to at least one active mobile connection and almost 11 million of these are mobile smartphones ${ }^{2}$.

Amongst the younger generation, online social activities, such as texting, online chatting, blogging, tweeting and accessing social network sites, dominate the mobile scene. Furthermore, the continuous development and depositing of information in the cloud promote sharing, updating and acquiring of information anytime, anywhere and with anyone. The continuous advances in cloud computing technology and the readily available access to resources in the cloud via mobile technology open the possibilities of applying these technologies in teaching and learning environments. MCC becomes the platform and access point between the learner, the teacher and the learning environment [6], [39], [4], [40], [31], [15], [43], [18], [22].

Ubiquity is an important driver of MCC and often cited as the rationale for using $\mathrm{MCC}$ in teaching and learning.

\section{Data portability and interoperability: integration of teaching resources}

Using MCC as the platform allows the cloud to be the access point [31], [15], [44], [41], [18], [22], thereby simplifying the management of information in terms of one entry point and backup. Using MCC as a platform promotes reusability and scalability; however, this also requires that current content and curricula be converted to content suitable for the cloud [6], [44], [36], [18].

Apart from converting current content to suitable content for the cloud environment, various commercial content providers already have applicable software and applications of which some are freely available and other services require subscription fees [5], [33], [34], [41], [18], [22]. Amongst these providers are Google, Microsoft, and Apple. As for LMS, products such as Blackboard and Moodle already supports MCC [15]. By identifying and using readily available applications, the integration of the MCC and current curricula could be quickened [15],[41],[18]. The examples provided by NETS (National Educational Technology Standards $)^{3}$ can be used to guide educators in the conversion of current curricula to content that can be used in the cloud. One of the major advantages of using MCC is the utilization of the processing power of the cloud in terms of shareability and portability of content; however, to optimally use and apply this, training for both the educators (this includes the facilitator) and the learners should take priority [15], [17]. The optimal use of its capabilities provides a platform that promotes amongst others the possibility of group projects, peer assessment, student developed presentations and simultaneous class discussions [4], [31], [15]. The factors that influence the adoption of $\mathrm{CC}$ as a platform in teaching and learning include:

1. Connectivity of the learners to the MCC services [31], [32], [33], [15], [16], [37].

2. Availability of applications offline [15].

3. Hardware requirements of the mobile devices [45], [32], [33], [15], [16], [37].

4. Availability of content and the management thereof [6], [5], [34], [44], [41].

5. Cooperative learning that includes availability, shareability and interaction amongst learners [6], [39], [4], [41], [36], [37], [46].

6. Computational capabilities requirements transferred from the mobile devices to services available in the cloud [39], [36], [46].

7. Management of services that includes subscription fees to paid services and data or network fees [33], [15], [41], [37]. 


\section{Privacy, security and ethics}

Using MCC as the platform mitigates the problems on content management in terms of backup and crash recovery [15]. However, despite the potential benefits of MCC with regard to data portability and interoperability the very nature of MCC may be problematic in terms of privacy, security and intellectual property as some or all of the resources exist in the mobile cloud [5], [8], [33], [34], [16], [18], [21], [46].

\section{Risk management and assessment}

Although the maintenance and management of the MCC reside on the side of the provider, it is still important to identify and address the risks of MCC, specifically in teaching and learning where the clients are often children [18],[47]. In the risk assessment of MCC the following are identified as supporting performance indicators at service level: (a) The user level - all devices able to logon to the MCC web server; (b) the application layer - portal with variety of application servers, single registration and sign-on; (c) logic level - real-time monitoring, data traffic monitoring; and (d) the physical layer - basic network environment, storage, devices, LRM [4].

As for the risk assessment of access and data location from the client side: (a) different roles of the users that can get access to the data in the MCC, (b) auditing of the data, (c) encryption procedures, and the (d) availability and moving of the data to another environment [15].

\subsubsection{Research opportunities}

Looking at the suggestions for future research there are suggestions for new applications, services and functions to be embedded in the cloud [1], existing services to be improved in terms of cost [5], scalability, flexibility and availability of elearning resources [6]. The analysis of the limitations noted in the current research and the suggestions for future research lead to the following insights on research opportunities.

Not enough research is done on the policies that govern privacy $^{4}$, security, ethics for the users (both learners and educators) that engage with the content, as well the protection of the intellectual property in the MCC platform [47].

The role of "big data" and how it can be utilized in the MCC learning environment to enhance learning [1,42] is under researched.

Not enough research is done on the human computer interaction technologies between the mobile user, (both learners and educators), and the MCC environment [24]. This was also evident in the security risks formulated by the participants in section 3.2.

Finally, the investigation of new uses of cloud computing enabled by dynamic, interactive knowledge management and the blending of services and prototypal set-ups developed to evaluate new technologies for environmentally driven education [39], warrants attention.

\subsection{Interview results}

The interview questions focused on obtaining data about the following aspects of MCCS: The cloud storage platforms that the participants have access to from their personal computers and those accessed from their mobile devices; the advantages and disadvantages as perceived by the participants; and then specifically those related to the use of MCCS in teaching and learning as well as the importance (severity) of the challenges. The interviews captured quantitative and qualitative data but focused on the qualitative data towards a richer understanding of the facilitators and teachers' perspective on MCC services. We found that the participants had access to the following cloud storage platforms: Google Drive, Microsoft One Drive and Dropbox, with Google Drive being the one that all the participants had access to. The participants were using all the platforms they had access to on their personal computers but mainly Google Drive from their mobile phones.

The general advantages noted were participants having access to documents from "anywhere" and the security issue of having a back-up when a device is lost or faulty. One participant mentioned the issue of having the data documents and photos off line. The following quotations offer a sense of the participants' sentiments:

- "Your information and documents are always accessible wherever you are, when there is connectivity."

- $\quad$ "A place where I store my documents and photos off line."

- "It helps in your views to be added in a group document. Members will know who the person adding information to the Microsoft Excel is for example."

- $\quad$ "It helps an individual to access large amounts of data/information and save your information when your device is lost."

- "One can access data from any smart device with internet connectivity!"

The advantages for teaching and learning mentioned, related to the ease of sharing documents like examination papers, solutions and teaching resources with other teachers and learners, and the ability to share large documents, which overcome the constraints of institutional e-mail system attachments. Social integration based on the ability to share information via non-institutional systems was considered important.

The general disadvantages related to cost and infrastructure. The fact that an internet connection is required is a constraint where internet access is not widely accessible or expensive. The disadvantages noted for relating specifically to teaching and learning were that not all schools have internet access or Wi-Fi and few have free internet access. Furthermore, teachers were not willing to use their own data at home for school-related purposes as evident from the following participant responses:

- "Internet access is expensive."

- "Not all schools have internet access or WiFi."

- "Teachers are not willing to get access on their own devices or use their own data at home."

- "Some group members could be lazy or slow to respond."

The security risks are formulated as follows:

- $\quad$ "People are scared to share information in the cloud. Not sure about the risks and dangers."

- "Budget and resistance to the use of ICT."

4 www.justice.gov.za/legislation/acts/2013-004.pdf 
The infrastructure risks are formulated as follows:

- "Not having enough gadgets and no connectivity to the internet."

- "Learners could store inappropriate photos or videos there."

Considering the participants responses as presented here, MCCS is a technology with untapped potential. The fact that only five of the 12 facilitators and one of the eight educators were aware of any policy guiding MCCS supports the findings from literature that policy formulation and awareness needs to be addressed.

The challenges mentioned most frequently were connectivity, security, privacy and cost. The drivers of using MCCS emerged as portability, backup, shareability and storage capacity, which suggests that institutional intervention, may be required to make full use of MCCS in teaching and learning. Although it is not specifically mentioned, the factors influencing mobile interaction between the MCC platform in general and the MCC learning platforms available for teaching and learning, can be identified as a one of the challenges. It is further evident that although the facilitators and educators are 'aware off' MCC as the platform used when mobile technology is used as a tool in teaching and learning, they are not confident in realizing the potential thereof nor are they instructed on the risks and potential dangers [25]-[28].

The enablers identified were training and the funding of broadband infrastructure and services.

\section{DISCUSSION AND CONCLUSION}

In this paper we provided an overview of existing cloud computing research relating to teaching and learning. We identified the instructional, architectural and theoretical angles as trends in MCC research. In terms of future research, the need for policies that govern privacy, security and ethics is highlighted together with the need for more research in human computer interaction designs as well as the use of big data to enhance learning. The analysis of the interview results confirmed the perceived advantages of ubiquity, portability and interoperability. Privacy and security have been identified as challenges in using MCCS but the concern relates to storage only. That could be because the educators are not aware of the other data management facilities offered by the cloud. We conclude that the barriers identified from the interviews, especially cost, scalability and governance (policies), are important issues to consider if CCS is to achieve its potential in driving research, development and innovation.

\section{$\mathrm{V}$ ACKNOWLEDGEMENT}

This work is based on the research supported by the South African Research Chairs Initiative of the Department of Science and Technology and National Research Foundation of South Africa (Grant No. 98564).

\section{REFERENCES}

M. Anshari, Y. Alas, and L. S. Guan, "Developing online learning resources: Big data, social networks, and cloud computing to support pervasive knowledge," Educ. Inf.
Technol., vol. 21, no. 6, pp. 1663-1677, Nov. 2016.

L. Caviglione, M. Coccoli, and V. Gianuzzi, "Opportunities, integration and issues of applying new technologies over elearning platforms," in Next Generation Networks and Services (NGNS), 2011 3rd International Conference on, 2011, pp. 1217.

[3] M. Baghdadi, K. Asad, and J. Raiyn, "Applying Advanced Technology Tools in Distance Learning - Case Study: Traffic Data and Road Safety," ACM, p. 389, 2012.

[4] D. W. Denton, "Enhancing Instruction through Constructivism, Cooperative Learning, and Cloud Computing," TechTrends, vol. 56, no. 4, pp. 34-41, Jul. 2012.

[5] J.-S. Cheng, E. Huang, and C.-L. Lin, "An E-Book Hub Service Based on a Cloud Platform," Int. Rev. Res. Open Distance Learn., vol. 13, no. 5, pp. 39-55, 2012.

[6] M. Anwar, H. Masud, and X. Huang, "An E-learning System Architecture based on Cloud Computing," World Acad. Sci. Eng. Technol., vol. 62, pp. 74-78, 2012.

[7] I. Golitsyna, "Application of Web Services in Teaching of ITDiscipline," Procedia - Soc. Behav. Sci., vol. 214, pp. 578-585, Dec. 2015.

[8] H. T. Dinh, C. Lee, D. Niyato, and P. Wang, "A survey of mobile cloud computing: architecture, applications, and approaches," Wirel. Commun. Mob. Comput., vol. 13, no. 18, pp. 1587-1611, Dec. 2013.

[9] M. J. Grant and A. Booth, "A typology of reviews: an analysis of 14 review types and associated methodologies," Heal. Inf. Libr. J., vol. 26, no. 2, pp. 91-108, Jun. 2009.

[10] C. Pickering, J. Grignon, R. Steven, D. Guitart, and J. Byrne, "Publishing not perishing: how research students transition from novice to knowledgeable using systematic quantitative literature reviews," Stud. High. Educ., vol. 40, no. 10, pp. 17561769, Nov. 2015.

[11] D. Gibson, "Assessing Teaching Skills with a Mobile Simulation," J. Digit. Learn. Teach. Educ., vol. 30, no. 1, pp. 4-10, Sep. 2013.

[12] L. Hong, K. Qian, and C.-C. Hung, "Work in progress: Multifaceted penetration of fast fourier transform by interactively analyzing real-world objects via mobile technology," in 2012 Frontiers in Education Conference Proceedings, 2012, pp. 12.

[13] J. M. Long, "Cloud-based teaching in an engineering-physics course," in 2015 IEEE Frontiers in Education Conference (FIE), 2015, pp. 1-8.

[14] D. S. Namdev, "ICT and Web Technology Based Innovations in Education Sector," Turkish Online J. Distance Educ., vol. 13, no. October, pp. 256-268, 2012.

[15] P. Pocatilu, F. Alecu, and M. Vetrici, "Measuring the efficiency of cloud computing for e-learning systems," WSEAS Trans. Comput., vol. 9, no. 1, pp. 42-51, 2010.

[16] P. Pocatilu, F. Alecu, and M. Vetrici, "Using Cloud Computing for E-learning Systems 2 Cloud Computing," 8th WSEAS Int. Conf. Data networks, Commun. Comput., vol. 9, no. 1, pp. 5459, 2009.

[17] H. Saliah-Hassane and A. Reuzeau, "Mobile open online laboratories: A way towards connectionist massive online laboratories with x-API (c-MOOLs)," in 2014 IEEE Frontiers in Education Conference (FIE) Proceedings, 2014, vol. 2015Febru, no. February, pp. 1-7.

[18] P. . Thomas, "Cloud computing: A potential paradigm for practising the scholarship," Electron. Libr., vol. 29, no. 2, pp. 214-224, Apr. 2011.

[19] N. Tillmann and J. Bishop, "Teaching programming on a mobile device," in Proceedings of the 17th ACM annual conference on Innovation and technology in computer science education - ITiCSE' '12, 2012, p. 404.

[20] S. Vasant and B. Mehta, "A Case Study: Embedding ICT for Effective Classroom Teaching \&amp; Learning," in Advances in Intelligent Systems and Computing, vol. 337, Springer International Publishing, 2015, pp. 541-547.

[21] M. Wang, Y. Chen, and M. J. Khan, "Mobile cloud learning for higher education: A case study of Moodle in the cloud," Int. Rev. Res. Open Distrib. Learn., vol. 15, no. 2, pp. 255-267, Apr. 
2014.

[22] Weiqing Zhao, Yafei Sun, and Lijuan Dai, "Improving computer basis teaching through mobile communication and cloud computing technology," in 2010 3rd International Conference on Advanced Computer Theory and Engineering(ICACTE), 2010, vol. 1, pp. V1-452-V1-454.

[23] J. Zhao et al., "A security framework in G-Hadoop for big data computing across distributed Cloud data centres," J. Comput. Syst. Sci., vol. 80, no. 5, pp. 994-1007, Aug. 2014.

[24] L. Crearie, "Human computer interaction (HCI) and internet residency: Implications for both personal life and teaching/learning," in Proceedings of the 13th International Conference on Cognition and Exploratory Learning in the Digital Age, CELDA 2016, 2016, no. Celda, pp. 307-310.

[25] L. Goosen and R. van der Merwe, "Keeping ICT in Education Community Engagement Relevant: Infinite Possibilities?," Liebenb. J., Gruner S. ICT Educ. SACLA 2017. Commun. Comput. Inf. Sci., vol. 730, pp. 113-127, 2017.

[26] L. Goosen and R. van der Merwe, "E-Learners, Teachers and Managers at e-Schools in South Africa," in ICEL2015-10th International Conference on e-Learning: ICEL 2015, 2015, p. 127.

[27] R. van der Merwe and D. van Heerden, "Using technology to gain knowledge: Development, implementation and evaluation of a mobile digital skills curriculum for educators," in Proceedings of the 2015 Annual Research Conference on South African Institute of Computer Scientists and Information Technologists, 2015, p. 42.

[28] J. van Biljon, J. Traxler, R. van der Merwe, and D. Van Heerden, "Curriculum Development for Mobile Digital Literacy Skills," J. Community Informatics, vol. 11, no. 3, 2015.

[29] T. Dong, Y. Ma, and L. Liu, "The Application of Cloud Computing in Universities' Education Information Resources Management," in Lecture Notes in Electrical Engineering, vol. 154 LNEE, Springer London, 2012, pp. 938-945.

[30] A. S. Hashim and W. F. W. Ahmad, "The Development of New Conceptual Model for MobileSchool," in 2012 Sixth UKSim/AMSS European Symposium on Computer Modeling and Simulation, 2012, vol. 3, pp. 517-522.

[31] Hong-qing Gao and Yan-jie Zhai, "System design of cloud computing based on Mobile Learning," in 2010 Third International Symposium on Knowledge Acquisition and Modeling, 2010, vol. 44, no. 8, pp. 239-242.

[32] D. Kakadia, P. Saripalli, and V. Varma, "MECCA: mobile, efficient cloud computing workload adoption framework using scheduler customization and workload migration decisions," in Proceedings of the first international workshop on Mobile cloud computing \& networking - MobileCloud '13, 2013, p. 41.

[33] P. Kalagiakos and P. Karampelas, "Cloud Computing learning," in 2011 5th International Conference on Application of Information and Communication Technologies (AICT), 2011, pp. $1-4$.

[34] K. Kartheeban and M. Venkatesulu, "Secure Cost Effective MLearning Through Cloud Computing," in Lecture Notes in Electrical Engineering, vol. 313, no. Lecture Notes in Electrical Engineering, Springer International Publishing, 2015, pp. 613-
622.

[35] J. Li, "Study on the Development of Mobile Learning Promoted by Cloud Computing," in 2010 2nd International Conference on Information Engineering and Computer Science, 2010, pp. $1-4$.

[36] A. Sotsenko, J. Zbick, M. Jansen, and M. Milrad, "Flexible and Contextualized Cloud Applications for Mobile Learning Scenarios," vol. 406, no. June, A. Peña-Ayala, Ed. Cham: Springer International Publishing, 2016, pp. 167-192.

[37] M. Wang, J. Xiao, Y. Chen, and W. Min, "Mobile Learning Design: The LTCS Model," in 2014 International Conference on Intelligent Environments, 2014, pp. 318-325.

[38] M. Zhang and J. Zhou, "Construction of Basic Education Cloud Computing Platform Based on Virtualization Technology," in In Intelligent Computing Methodologies. Springer International Publishing., vol. 8589 LNAI, 2014, pp. 709-716.

[39] L. Caviglione, M. Coccoli, and V. Gianuzzi, "Opportunities, integration and issues of applying new technologies over elearning platforms," in 2011 3rd International Conference on Next Generation Networks and Services (NGNS), 2011, pp. 1217.

[40] N. Fernando, S. W. Loke, and W. Rahayu, "Mobile cloud computing: A survey," Futur. Gener. Comput. Syst., vol. 29, no. 1, pp. 84-106, Jan. 2013.

[41] N. Selviandro and Z. A. Hasibuan, "Cloud-Based E-Learning: A Proposed Model and Benefits by Using E-Learning Based on Cloud Computing for Educational Institution," in Lecture Notes in Computer Science (including subseries Lecture Notes in Artificial Intelligence and Lecture Notes in Bioinformatics), vol. 7804 LNCS, 2013, pp. 192-201.

[42] S. S. C. Young and H. C. Hung, "Coping with the challenges of open online education in Chinese societies in the mobile era: NTHU OCW as a case study," Int. Rev. Res. Open Distrib. Learn., vol. 15, no. 3, pp. 158-184, Jun. 2014.

[43] S. C. Satapathy, A. Govardhan, K. S. Raju, and J. K. Mandal, Emerging ICT for Bridging the Future - Proceedings of the 49th Annual Convention of the Computer Society of India CSI Volume 2, vol. 338, no. January 2015. Cham: Springer International Publishing, 2015.

[44] G. Riahi, "E-learning Systems Based on Cloud Computing: A Review," Procedia Comput. Sci., vol. 62, no. 2, pp. 352-359, 2015.

[45] Hong-qing Gao and Yan-jie Zhai, "System design of cloud computing based on Mobile Learning," in 2010 Third International Symposium on Knowledge Acquisition and Modeling, 2010, vol. 44, no. 8, pp. 239-242.

[46] Y. Wang, I.-R. Chen, and D.-C. Wang, "A Survey of Mobile Cloud Computing Applications: Perspectives and Challenges," Wirel. Pers. Commun., vol. 80, no. 4, pp. 1607-1623, Feb. 2015.

[47] J. Traxler, "Students and mobile devices," ALT-J, vol. 18, no. 2, pp. 149-160, Jul. 2010.

[48] G. Suciu, A. Vulpe, and G. Todoran, "Cloud Computing and Big Data as Convergent Technologies for Mobile E-Learning," in The International Scientific Conference eLearning and Software for Education, 2014, vol. 4, pp. 113-120. 